\title{
Noninvasive Brain Stimulation Protocols in the Treatment of Epilepsy: Current State and Perspectives
}

\author{
Michael A. Nitsche and Walter Paulus \\ Department of Clinical Neurophysiology, Georg-August-University, 37099 Goettingen, Germany
}

\begin{abstract}
Summary: In epileptic seizures, there is an enhanced probability of neuronal networks to fire synchronously at high frequency, initiated by a paroxysmal depolarisation shift. Reducing neuronal excitability is a common target of antiepileptic therapies. Beyond or in addition to pharmacological interventions, excitability-reducing brain stimulation is pursued as an alternative therapeutic approach. Hereby, noninvasive brain stimulation tools, such as transcranial magnetic stimulation (TMS) and transcranial direct current stim-
\end{abstract}

ulation (tDCS), have gained increased interest as efficient tools to modulate cortical excitability and activity. In animal models, stimulation-induced cortical excitability diminution has been shown to be suited to reduce seizures. Clinical studies conducted to date, however, have shown mixed results. Reasons for this, as well as possible optimization strategies that might lead to more efficient future stimulation protocols, will be discussed. Key Words: Epilepsy, brain stimulation, TMS, tDCS, humans.

\section{INTRODUCTION}

The pathophysiological substrate of epilepsies and the proneness to develop seizures is an enhanced cortical excitability, leading to paroxysmal depolarisation shifts, an enhanced probability of high-frequent and hypersynchronous activity of small neuronal networks, and an abnormal spreading of this pathological activity along cortico-cortical and cortico-subcortical neuronal connections. ${ }^{1-3}$ The common feature of antiepileptic therapies is thus the reduction of any pathological hyperactivity by either enhancing neuronal inhibition or reducing excitation. Drugs that block voltage-dependent ion-channels, excitatory N-methyl-D-aspartate (NMDA)-receptors, or enhance gamma-aminobutyric acid (GABA)ergic activity have been shown to have a profound ability to suppress the development of seizures. ${ }^{4}$ Alternatively, epilepsy surgery aims to remove the epileptogenic regions and thus prevent the development of epileptic activity by destroying the pathological network components. ${ }^{5} \mathrm{Al}-$ though effective, these currently available therapeutic approaches have some drawbacks: treatment with antiepileptic drugs does not simply diminish pathological

Address correspondence and reprint requests to: Michael A. Nitsche, Georg-August-University, Department of Clinical Neurophysiology, Robert-Koch-Strasse 40, 37099 Goettingen, Germany. E-mail: mnitsch1@gwdg.de. excitability of the epileptogenic region but affects the whole brain, which might compromise normal functioning and result in cognitive impairment, a common side effect of pharmacological treatment of epilepsy. Epilepsy surgery is-although currently a routine procedure for patients with pharmacoresistant focal epilepsy-not without risk: it might not be able to, in each case, remove the epileptogenic region selectively without affecting normal functioning brain areas and thus also impair cognitive and behavioral functioning. Moreover, about 30\% of patients continue to have seizures when taking antiepileptic medications. ${ }^{6}$ Epilepsy surgery cannot be performed in all cases for these patients, and even for those in whom surgery is possible, after surgery, $30 \%$ to $50 \%$ of patients are not free of seizures. ${ }^{7}$ Thus, there is a definite need for adjunctive therapeutic approaches, which ideally should have a focal effect and be noninvasive.

This review is dedicated to noninvasive brain stimulation procedures, namely repetitive transcranial magnetic stimulation (rTMS) and transcranial direct current stimulation (tDCS), which at least theoretically fulfil some requirements needed for such a therapeutic tool. Whereas the effect of rTMS on epilepsy has been studied now for about 10 years, tDCS has relatively recently started to come into awareness as a possible agent for treating epilepsy. 


\section{rTMS FOR THE TREATMENT OF EPILEPSY}

\section{Technical aspects and pathophysiology}

Transcranial magnetic stimulation (TMS) was first described in 1985 as an effective noninvasive and painless method for stimulation of the human brain. ${ }^{8}$ A shortlasting, strong magnetic stimulus delivered from a coil induces an electric current flow in the brain strong enough to elicit action potentials in cortical neurons. The magnetic field is simply used to pass the high-intensity pulses without pain induction through the skull. This cortical excitation results in action potentials, the effect of which can be monitored indirectly by the resulting muscle evoked potentials (MEPs), if applied over the primary motor cortex.

In animal experiments, repetitive activation of neurons by electrical stimulation induces long-lasting cortical excitability alterations. Depending on the frequency of stimulation, cortical excitability diminutions or enhancements, named long-term depression (LTD) or long-term potentiation (LTP), are induced, which remain stable for hours or days after the end of stimulation..$^{9-11}$ Lowfrequency stimulation results in LTD, whereas highfrequency stimulation induces LTP. Similar effects are induced in the human cerebral cortex by low- and highfrequency rTMS. Here, stimulation frequencies at or below $1 \mathrm{~Hz}$ induce inhibition, whereas higher frequencies induce facilitation - the latter, however, are shorter than the inhibitory effects. ${ }^{12,13}$ New protocols, whose therapeutic potentials to date have not been explored, induce longer lasting after effects. Excitability changes are achieved by a qualitatively different stimulation protocol, namely continuous or intermittent theta burst stimulation (TBS). ${ }^{14}$

It was demonstrated in hippocampal and neocortical rat slices that low-frequency $(1 \mathrm{~Hz})$ electrical stimulation is indeed able to prevent interictal epileptic discharges and epilepsy-like events in an intensity-, frequency-, and distance-dependent manner. ${ }^{15,16}$ Moreover, these effects remain after the end of stimulation and are NMDA receptor-dependent, thus indicating that LTD-inducing protocols might have antiepileptic properties. Thus, the application of low-frequency rTMS for treating epilepsy in humans seems promising.

\section{Clinical trials}

Open-label studies and case reports. In the first open-label study, Tergau et $\mathrm{al}^{17}$ explored the impact of low-frequency rTMS, applied for 5 consecutive days with a frequency of $0.3 \mathrm{~Hz}$, on seizure frequency in nine patients with focal, pharmacoresistant epilepsy. Stimulation was performed with a nonfocal round magnetic coil over the vertex irrespective of localization of the epileptogenic zone. rTMS resulted in a clear reduction of the number of epileptic seizures per week, which was still prominent four weeks after intervention. Succeeding studies delivered mixed results.

In some case reports, a reduction of seizure frequency and epileptogenic discharges by rTMS was demonstrated. In three patients with epilepsia partialis continua and one other patient with focal epilepsy, low-frequency rTMS with a focal coil positioned over the presumed epileptogenic zone with relatively low intensity ${ }^{18-21}$ (Table 1) reduced seizure frequency and epileptic discharges. However, in two other patients with epilepsia partialis continua, low-frequency rTMS of similar intensity and duration over the epileptogenic zone was without effect. ${ }^{22}$ In two patients with focal and primary generalized epilepsy, rTMS was performed over the vertex; here, rTMS induced a reduction of interepileptic discharges. ${ }^{23,24}$ Seizure frequency could not be determined for the patient with focal epilepsy because he was already seizure free before intervention. Seizure frequency was not reduced in the patient with primary generalized epilepsy; however, this patient received time-locked 5 $\mathrm{Hz}$ rTMS at the beginning of spike wave discharges, so this stimulation protocol, which only reduced discharge duration, is not easy to compare with the others.

Interestingly, in two patients with epilepsia partialis continua, high-frequency rTMS was applied over the epileptogenic zone and improved seizure frequency in one of these patients. ${ }^{25}$

Taken together, the results of the case reports suggest the efficacy of rTMS to reduce epileptic discharges and improve clinical state in some but not all patients. The treatment protocols differ in terms of focality of stimulation, application of rTMS over the epileptogenic zone or the vertex, stimulation intensity, repetition rate and frequency, as well as etiology of epilepsy and antiepileptic medication. No clear picture emerges in terms of which stimulation protocol might be optimal and which patients benefit most from stimulation. It should be stressed, however, that not only low-frequency rTMS but also high-frequency stimulation might have a beneficial effect on seizure frequency, as shown by the case reports of Graff-Guerrero et al. ${ }^{18}$ Of course, the case reports were not sham-controlled; thus, it is difficult to evaluate the contribution of a placebo effect to the results.

Overall, the available open-label studies show a reduction of seizure frequency and epileptic discharges, if recorded, by rTMS with stimulation frequencies of $1 \mathrm{~Hz}$ or lower. ${ }^{26-31}$ In all of these studies, patients with focal epilepsy were treated (Table 1). In one study performed in patients with epilepsia partialis continua, low-frequency rTMS was primed with high-frequency rTMS to improve the efficacy of low-frequency rTMS to suppress cortical excitability, ${ }^{32}$ but this specific protocol was not clearly superior to low-frequency stimulation only. In the only study exploring the effect of a higher rTMS frequency $(5 \mathrm{~Hz})$ on seizure frequency, the seizure-reducing 
effect was relatively short lasting. ${ }^{33}$ Low-frequency rTMS was performed between 0.3 and $0.9 \mathrm{~Hz}$, but the specific frequency had no impact on the efficacy of stimulation when comparing the different studies. The focality of stimulation is determined by the position of the coil relative to the epileptogenic region and the focality of the stimulation coil. In one study, rTMS of the epileptogenic zone was compared with vertex stimulation ${ }^{34}$; only stimulation of the epileptogenic zone was effective, favoring a focused stimulation in focal epilepsy. Focality of the coil was not compared within a single study. Because two of the open-label studies using focal figure-of-eight coils resulted in relatively moderate effects as compared to other studies in which the round nonfocal coil was used, the latter might be more effective. However, since the respective studies also differed with regard to other stimulation parameters and patient characteristics, this statement should be taken with caution. The intensity of stimulation was between $90 \%$ and $120 \%$ of motor threshold, and the number of stimuli applied was between 100 and 1000. Comparison of the efficacy of stimulation to reduce seizures is slightly in favor of stronger and longer stimulation. However, since other parameters were not identical among the various studies (with the exception of one study, in which different numbers of stimuli were compared directly ${ }^{31}$ ), this statement is also somewhat preliminary.

Controlled clinical studies. For the three randomized, double-blinded and sham-controlled studies, only one resulted in a significant reduction of seizure frequency and interictal discharges, ${ }^{35}$ whereas in another study a trend for a reduction of epileptic seizures was found, ${ }^{36}$ and in a third study only significantly reduced epileptiform discharges were documented. ${ }^{37}$ Definitive reasons for these heterogeneous results are difficult to state because the studies differ in more than one aspect (Table 1). In the studies conducted by Fregni et al. ${ }^{35}$ and Theodore et al., ${ }^{36}$ rTMS intensity was stronger than in the study conducted by Cantello et al., ${ }^{37}$ and more stimuli were applied. Moreover, in the former studies, the epileptogenic zone was stimulated, whereas in the latter study, stimulation over the vertex was performed. Thus it could be argued that more intense rTMS and rTMS over the epileptogenic zone might be preferable. However, Fregni et al. ${ }^{35}$ and Theodore et al.$^{36}$ included only patients with focal epilepsy, whereas patients with primarily generalized epilepsies also participated in the study conducted by Cantello et al. ${ }^{37}$ Thus, it cannot be excluded that the type of epilepsy has an impact on the proneness to profit from rTMS. From a pathophysiological perspective, it would make sense that focal epilepsies with a cortical origin, which will be more easily influenced by rTMS, might profit more from rTMS than primary generalized epilepsies with a subcortical origin much more distant to the electrical current flow induced by TMS.

\section{Determinants of clinical efficacy of rTMS}

Taken together, therapeutic rTMS studies in epilepsy show some efficacy to improve clinical symptoms, but in most studies the effects are rather weak. Thus, optimizing strategies are needed. With regard to optimum suited protocols, it seems that stronger, longer rTMS and rTMS over the epileptogenic focus and not at some distant area might be superior. Even less is known about the impact of the focality of the coil, current flow direction, and optimal suited frequency of stimulation. It might be that high-frequency stimulation has a disruptive effect on epileptic seizures, while low-frequency rTMS prevents seizure induction. However, this assumption is more derived from presumed mechanisms than supported by controlled studies. Finally, it is not known whether optimum stimulation parameters differ between focal and primary generalized epilepsies or whether the specific antiepileptic medication has an effect on the efficacy of rTMS. Indeed, antiepileptic medication might matter: it has been shown that antiepileptic drugs affect the impact of rTMS on cortical excitability. ${ }^{38,39}$ Moreover, valproate medication may reverse the effects of $1 \mathrm{~Hz}$ rTMS from inhibition into facilitation in patients with juvenile myoclonic epilepsy. ${ }^{40}$

Studies addressing these unsolved problems are urgently needed, and future therapeutic studies should be planned in a way that enables optimization of rTMS protocols.

\section{tDCS FOR THE TREATMENT OF EPILEPSY}

\section{Technical aspects and pathophysiology}

Compared to rTMS, tDCS is a relatively old technique. In the 1960s it was demonstrated in animal experiments that a tonic cortical direct current (DC) stimulation can diminish or enhance cortical excitability and activity, dependent on current flow direction. ${ }^{41}$ Subsequently, the technique was adapted for noninvasive stimulation in humans, but at that time its effects were mainly tested clinically, and not directly electrophysiologically. An antidepressive effect of DC stimulation was suggested, but this was not substantiated in all studies. ${ }^{42,43}$ Recently, tDCS protocols were developed for noninvasive stimulation in humans, which induce polarity-dependent cortical excitability shifts stable for up to an hour after stimulation ${ }^{44,45}$; these after effects of tDCS can be relevantly prolonged (for hours) by pharmacological agents. ${ }^{46-48}$ Thus, reducing cortical excitability via tDCS offers a promising approach to diminish epileptic activity and seizure frequency.

The efficacy of DC stimulation to suppress epileptiform activity and epileptic seizures was demonstrated in animal experiments. In rat brain hippocampal slice ex- 
Table 1. Impact of rTMS on Epileptic Seizures and Interical Discharges

\begin{tabular}{|c|c|c|c|c|c|}
\hline Article & Type of Study & Epilepsy & Coil Form & $\begin{array}{l}\text { Frequency } \\
\quad(\mathrm{Hz})\end{array}$ & Intensity \\
\hline $\begin{array}{l}\text { Cantello et al., } \\
2007^{37}\end{array}$ & $\begin{array}{l}\text { Randomized, double-blinded, } \\
\text { sham-controlled }\end{array}$ & $\begin{array}{l}\text { Focal, primary } \\
\text { generalized }\end{array}$ & Round & 0.3 & $100 \% \mathrm{MT}$ \\
\hline $\begin{array}{l}\text { Fregni et al., } \\
\qquad 2006^{35}\end{array}$ & $\begin{array}{l}\text { Randomized, double-blinded, } \\
\text { sham-controlled }\end{array}$ & Focal & Figure-of-eight & 1 & $\begin{array}{l}70 \% \text { Max. } \\
\text { stimulator } \\
\text { output }\end{array}$ \\
\hline $\begin{array}{l}\text { Theodore et al., } \\
2002^{36}\end{array}$ & $\begin{array}{l}\text { Randomized, double-blinded, } \\
\text { sham-controlled }\end{array}$ & Focal & Figure-of-eight & 1 & $120 \% \mathrm{rMT}$ \\
\hline Joo et al., $2007^{31}$ & Randomized & Focal & $\begin{array}{l}\text { Round or } \\
\text { figure-of-eight }\end{array}$ & 0.5 & $100 \%$ rMT \\
\hline $\begin{array}{l}\text { Brasil-Neto et al., } \\
2004^{26}\end{array}$ & Open label & Focal & Round & 0.3 & $95 \% \mathrm{rMT}$ \\
\hline $\begin{array}{l}\text { Brighina et al., } \\
2006^{32}\end{array}$ & Open label & Focal & Figure-of-eight & 5 & $90 \%$ rMT \\
\hline $\begin{array}{l}\text { Daniele et al., } \\
2003^{34}\end{array}$ & Open label & Focal & Figure-of-eight & 0.5 & $90 \% \mathrm{MT}$ \\
\hline $\begin{array}{l}\text { Fregni et al., } \\
2005^{27}\end{array}$ & Open label & Focal & Figure-of-eight & 0.5 & $\begin{array}{l}\text { 65\% Max. } \\
\text { stimulator } \\
\text { output }\end{array}$ \\
\hline$\underset{2005^{28}}{\text { Kinoshita et al., }}$ & Open label & Focal & Round & 0.9 & $90 \%$ rMT \\
\hline $\begin{array}{l}\text { Rotenberg et al., } \\
2008 b^{29}\end{array}$ & Open label & $\begin{array}{l}\text { Epilepsia partialis } \\
\text { continua }\end{array}$ & Figure-of-eight & $1,20-100$ & $100 \% \mathrm{MT}$ \\
\hline $\begin{array}{l}\text { Santiago-Rodriguez } \\
\text { et al., } 2008^{30}\end{array}$ & Open label & Focal neocortical & Figure-of-eight & 0.5 & $120 \% \mathrm{MT}$ \\
\hline $\begin{array}{l}\text { Tergau et al., } \\
1999^{17}\end{array}$ & Open label & Focal & Round & 0.3 & $100 \% \mathrm{MT}$ \\
\hline Cantello, $2002^{24}$ & Case report & $\begin{array}{l}\text { Primary } \\
\text { generalized }\end{array}$ & & 5 & $120 \% \mathrm{rMT}$ \\
\hline $\begin{array}{l}\text { Graff-Guerrero et } \\
\text { al., } 2004^{25}\end{array}$ & Case report & $\begin{array}{l}\text { Epilepsia partialis } \\
\text { continua }\end{array}$ & Figure-of-eight & 20 & $\begin{array}{l}50 \% \mathrm{MO} \\
128 \% \mathrm{MT}\end{array}$ \\
\hline$\underset{2006^{23}}{\text { Mecarelli et al., }}$ & Case report, sham controlled & Focal & Round & 0.33 & $100 \%$ rMT \\
\hline $\begin{array}{l}\text { Menkes and } \\
\text { Gruenthal, } \\
2000^{18}\end{array}$ & Case report & Focal & Round & 0.5 & $95 \% \mathrm{rMT}$ \\
\hline $\begin{array}{l}\text { Misawa et al., } \\
2005^{19}\end{array}$ & Case report & $\begin{array}{l}\text { Epilepsia partialis } \\
\text { continua }\end{array}$ & Figure-of-eight & 0.5 & $90 \% \mathrm{rMT}$ \\
\hline Rossi et al., $2004^{20}$ & Case report & $\begin{array}{l}\text { Epilepsia partialis } \\
\text { continua }\end{array}$ & Figure-of-eight & 1 & $90 \%$ rMT \\
\hline $\begin{array}{l}\text { Rotenberg et al., } \\
2008 \mathrm{a}^{21}\end{array}$ & Case report & $\begin{array}{l}\text { Epilepsia partialis } \\
\text { continua }\end{array}$ & Figure-of-eight & 1 & $100 \% \mathrm{MT}$ \\
\hline
\end{tabular}

Depicted are the case reports, open-label studies, and sham-controlled studies exploring the efficacy of rTMS as an anticonvulsive agent. Studies are shown in alphabetical order with details of the epilepsy syndrome, specific protocol applied, and effects on seizure and interictal discharges. $\mathrm{MT}=$ motor threshold; $\mathrm{FCz}=$ frontocentral electrode according to the 1020 system; $\mathrm{MO}=$ max. stimulator output; N.A. $=$ not available; $\mathrm{rMT}=$ resting motor threshold; $\mathrm{PCz}=$ parietocentral electrode according to the 1020 system.

periments, weak DC stimulation abolishes epileptiform activity in the low $\mathrm{Ca}+$ model dependent on stimulation polarity during DC stimulation. ${ }^{49}$ In vivo rat experiments resulted in similar effects: cathodal tDCS over the sensorimotor cortex of behaving rats increased the seizure threshold in the ramp model of epileptic seizures, ${ }^{50}$ while anodal excitability-enhancing tDCS was without effect. These seizure threshold enhancements depended on current strength and were significant for up to 90 minutes after tDCS. Their magnitude was in the range of that provided by antiepileptic medication.

\section{Clinical trials}

In the first pilot study, the efficacy of tDCS to reduce epileptoform activity and seizure frequency in humans was explored in pharmaco-resistant patients with focal epilepsy due to malformations of cortical development. In this double-blinded, sham-controlled, randomized 
Table 1. Continued

\begin{tabular}{|c|c|c|c|c|}
\hline $\begin{array}{l}\text { Number of } \\
\text { Stimuli }\end{array}$ & $\begin{array}{l}\text { Repetition } \\
\text { (Days) }\end{array}$ & Coil Localisation & Seizures & Epileptiform Discharges \\
\hline 1000 & 5 & Vertex & No reduction & Reduction \\
\hline 1200 & 5 & $\begin{array}{l}\text { Epileptogenic focus } \\
\quad \text { or } \mathrm{Cz}\end{array}$ & Reduction for 2 months & Reduction \\
\hline $\begin{array}{l}900 \text { Twice } \\
\text { daily }\end{array}$ & 7 & Epileptic focus & Trend for reduction & Not recorded \\
\hline $1500 / 3000$ & 5 & $\begin{array}{l}\text { Epileptogenic focus } \\
\text { or non-focal }\end{array}$ & $\begin{array}{l}\text { Trend for reduction, stronger with } \\
\text { more stimuli, independent from } \\
\text { coil localisation }\end{array}$ & Reduction \\
\hline 100 & $\begin{array}{l}\text { Ca. } 45 \text { over } \\
3 \text { months }\end{array}$ & Vertex & Reduction & Not recorded \\
\hline 100 & 20 & Near inion & Reduction only during protocol & Not recorded \\
\hline 800 & $\begin{array}{l}\text { Biweekly for } \\
4 \text { weeks }\end{array}$ & $\begin{array}{l}\text { Epileptogenic focus } \\
\text { or } \mathrm{Cz}\end{array}$ & $\begin{array}{l}\text { Reduction only by stimulation } \\
\text { over the epileptogenic region }\end{array}$ & Not recorded \\
\hline 600 & None & $\begin{array}{l}\text { Epileptogenic focus } \\
\text { or } \mathrm{Cz}\end{array}$ & Reduction for 1 month & Reduction for 1 month \\
\hline $\begin{array}{l}1000 \text { Twice } \\
\text { daily }\end{array}$ & 5 & $\mathrm{FCz}, \mathrm{PCz}$ & Reduction & Not recorded \\
\hline diverse & Different & Epileptogenic focus & $\begin{array}{l}\text { Reduction, in most cases short- } \\
\text { lasting }\end{array}$ & N.A. \\
\hline 900 & 14 & Epileptic focus & Reduction & No reduction \\
\hline 1000 & 5 & Vertex & Reduction & Not recorded \\
\hline Unknown & $\begin{array}{l}\text { Beginning of } \\
\text { spike wave } \\
\text { discharge }\end{array}$ & & No reduction & $\begin{array}{l}\text { Reduction of duarion of } \\
\text { spike wave discharge }\end{array}$ \\
\hline 40 & 15 & Epileptogenic focus & Reduction in one of two patients & Reduction \\
\hline $\begin{array}{l}500 \text { Twice } \\
\text { daily }\end{array}$ & 5 & Vertex & $\begin{array}{l}\text { No reduction (but seizure-free } \\
\text { before) }\end{array}$ & Reduction \\
\hline 100 & $\begin{array}{l}\text { Twice a } \\
\text { week for } \\
\text { four weeks }\end{array}$ & Epileptogenic focus & Reduction & Reduction \\
\hline 100 & none & Epileptogenic focus & Reduction for 2 months & Not recorded \\
\hline 900 & None & $\begin{array}{l}\text { Epileptogenic } \\
\text { Focus }\end{array}$ & Reduction & Reduction \\
\hline 1800 & 9 & Epileptogenic focus & $\begin{array}{l}\text { Reduction duration of seizures } \\
\text { only during stimulation }\end{array}$ & Reduction \\
\hline
\end{tabular}

study, cathodal excitability-reducing tDCS was applied once for 20 minutes with a current strength of $1 \mathrm{~mA}$ over the presumed epileptogenic focus. After real tDCS, the frequency of epileptiform discharges was significantly reduced. Moreover, in the month after real tDCS, the number of epileptic seizures decreased trend-wise while it was stable in the group treated with sham tDCS. ${ }^{51}$

\section{Parameters determining clinical efficacy of tDCS}

From these results, it can be concluded that tDCS might be a promising noninvasive stimulation paradigm to reduce seizures in patients with focal epilepsy, especially since the applied current density was relatively weak and administered only once, which is less than the protocols performed in most rTMS studies. However, some questions to be solved remain: optimal stimulation duration, repetition rate, and stimulation strength and position of the reference electrode (which is important because the efficacy of tDCS depends on current flow direction) have not been clarified to date. Moreover, whether extended stimulation protocols will have a significant impact on seizure frequency has not 
been explored. Thus, as compared with rTMS, tDCS is currently much more in its infancy.

\section{CONCLUSION}

Since a significant number of epilepsy patients still cannot be sufficiently treated with pharmacological therapy or epilepsy surgery, there is a need for adjunctive therapies. For this purpose, rTMS and tDCS might evolve as promising tools. The principle mechanism of action of both tools might be an induction of LTD-like effects-diminishing cortical excitability and thus reducing the probability of paroxysmal activity in epileptogenic cortical regions. This mechanism, i.e., a reduction of cortical excitability, shares some similarities with the pharmacological treatment of epilepsies, but might differ qualitatively from invasive brain stimulation protocols like deep brain stimulation, which are thought to induce depolarization blocks. This difference with regard to invasive brain stimulation protocols might also account for the different effects after termination of stimulation, i.e. outlasting effects of rTMS versus rapid abolition of the effects after termination of brain stimulation with invasive protocols. The lasting after-effects of rTMS might enable this tool to become practicable as an adjunctive therapy for epilepsy in future. The presumed focality of the effects of rTMS and tDCS might be an advantage in focal epilepsy but limit its efficacy in primary generalized epilepsy.

However, the treatment studies performed with rTMS and tDCS to date show mixed results. This might be due to the suboptimal or simply underpowered protocols conducted so far. Moreover, in most of the studies, pharmacoresistant patients were treated, which might have resulted in an underestimation of the efficacy of the techniques to treat depression. To evaluate the full potential of these tools to treat epilepsies, studies are needed that are suited to generate information about optimized stimulation protocols: these should systematically evaluate the impact of coil/electrode position, focality of stimulation, stimulation strength/frequency, number of stimuli, repetition rate of stimulation protocols, as well as epilepsy syndrome and pharmacological treatment on the efficacy of stimulation. The respective studies should preferably be conducted in a sham-controlled, randomized, and double-blinded manner to identify placebo effects, which might be relevant, especially given the relatively poor correlation between seizure frequency reported by the patients and real seizure frequency. Only these studies will allow for the determination of the real potential of noninvasive brain stimulation tools to treat epilepsy. For tDCS, a double-blinded, sham-controlled, crossover, multicenter study has recently benn started in order to evaluate the potential of daily repeated tDCS for reducing seizure frequency in patients with focal epilepsy.
Apart from minor side effects, such as headache and tiredness, which were reported after both rTMS and tDCS, ${ }^{52,53}$ both stimulation tools result in relatively low rates of side effects. With regard to the risk of seizure induction, for rTMS this factor seems to be primarily important as concerns high frequency excitability-enhancing rTMS protocols. Most of the rTMS protocols performed for the treatment of epilspsy are, however, using low-stimulation frequencies. For these protocols, seizures elicited by rTMS have not been described. Although improbable, a risk for seizure induction by lowfrequency stimulation protocols cannot be ruled out completely, since the direction of excitability modulation induced seems to depend on basal cortical activity, and thus, in some subjects, even slow rTMS might enhance excitability. ${ }^{54}$ Similarly, no seizure induction has been reported to date for tDCS in humans or animal seizure models. ${ }^{50,52}$ However, because excitability-reducing cathodal tDCS includes anodal excitability-enhancing tDCS of another cortical area in the standard stimulation protocols, such a risk cannot be ruled out completely, but might be circumvented by the use of either large, ineffective reference electrodes ${ }^{55}$ or an extracephalic reference.

Because rTMS and tDCS have relatively low rates of side effects, may have some advantages over pharmacological treatment, evoke focal and not global reductions of cortical excitability, are nondestructive (as compared to surgical procedures), and have resulted in promising outcomes in some pilot studies, it should be worth the effort to explore the therapeutic potential of these noninvasive brain stimulation tools to a larger extent.

\section{REFERENCES}

1. Stafstrom CE. Epilepsy: a review of selected clinical syndromes and advances in basic science. J Cereb Blood Flow Metab 2006; 26:983-1004

2. Steriade M, Contreras D. Spike-wave complexes and fast components of cortically generated seizures. I. Role of neocortex and thalamus. J Neurophysiol 1998;80:1439-1455.

3. Dudek FE, Sutula TP. Epileptogenesis in the dentate gyrus: a critical perspective. Prog Brain Res 2007;163:755-773.

4. Levy RH, Mattson RH, Meldrum BS, Perucca E, eds. Antiepileptic Drugs, 5th ed. Philadelphia, PA: Lippincott Williams \& Wilkins, 2002.

5. Schramm J, Clusmann H. The surgery of epilepsy. Neurosurgery 2008;62(Suppl 2):463-481.

6. Schiller Y, Najjar Y. Quantifying the response to antiepileptic drugs: effect of past treatment history. Neurology 2008;70:54-65.

7. Spencer S, Huh L. Outcomes of epilepsy surgery in adults and children. Lancet Neurol 2008;7:525-537.

8. Barker AT, Jalinous R, Freeston IL. Non-invasive magnetic stimulation of human motor cortex. Lancet 1985;1:1106-1107.

9. Malenka RC, Bear MF. LTP and LTD: an embarrassment of riches. Neuron 2004;44:5-21.

10. Massey PV, Bashir ZI. Long-term depression: multiple forms and implications for brain function. Trends Neurosci 2007;30:176-184.

11. Raymond CR. LTP forms 1, 2 and 3: different mechanisms for the "long" in long-term potentiation. Trends Neurosci 2007;30:167-175.

12. Fitzgerald PB, Brown TL, Marston NA, et al. Motor cortical excitability and clinical response to rTMS in depression. J Affect Disord 2004;82:71-76. 
13. Pascual-Leone A, Tormos JM, Keenan J, Tarazona F, Cañete C, Catalá MD. Study and modulation of human cortical excitability with transcranial magnetic stimulation. J Clin Neurophysiol 1998;15:333-343.

14. Huang YZ, Edwards MJ, Rounis E, Bhatia KP, Rothwell JC. Theta burst stimulation of the human motor cortex. Neuron 2005;45:201206.

15. Albensi BC, Ata G, Schmidt E, Waterman JD, Janigro D. Activation of long-term synaptic plasticity causes suppression of epileptiform activity in rat hippocampal slices. Brain Res 2004;998:56-64.

16. Schiller Y, Bankirer Y. Cellular mechanisms underlying antiepileptic effects of low- and high-frequency electrical stimulation in acute epilepsy in neocortical brain slices in vitro. J Neurophysiol 2007;97:1887-1902.

17. Tergau F, Naumann U, Paulus W, Steinhoff BJ. Low-frequency repetitive transcranial magnetic stimulation improves intractable epilepsy. Lancet 1999;353:2209.

18. Menkes DL, Gruenthal M. Slow-frequency repetitive transcranial magnetic stimulation in a patient with focal cortical dysplasia. Epilepsia 2000;41:240-242.

19. Misawa S, Kuwabara S, Shibuya K, Mamada K, Hattori T. Lowfrequency transcranial magnetic stimulation for epilepsia partialis continua due to cortical dysplasia. J Neurol Sci 2005;234:37-39.

20. Rossi S, Ulivelli M, Bartalini S, et al. Reduction of cortical myoclonus-related epileptic activity following slow-frequency rTMS. Neuroreport 2004;15:293-296.

21. Rotenberg A, Depositario-Cabacar D, Bae EH, Harini C, PascualLeone A, Takeoka M. Transient suppression of seizures by repetitive transcranial magnetic stimulation in a case of Rasmussen's encephalitis. Epilepsy Behav 2008;13:260-262.

22. Morales OG, Henry ME, Nobler MS, Wassermann EM, Lisanby $\mathrm{SH}$. Electroconvulsive therapy and repetitive transcranial magnetic stimulation in children and adolescents: a review and report of two cases of epilepsia partialis continua. Child Adolesc Psychiatr Clin N Am 2005;14:193-210.

23. Mecarelli O, Gregori B, Gilio F, et al. Effects of repetitive transcranial magnetic stimulation in a patient with fixation-off sensitivity. Exp Brain Res 2006;173:180-184.

24. Cantello R. Prolonged cortical silent period after transcranial magnetic stimulation in generalized epilepsy. Neurology 2002;58:1135.

25. Graff-Guerrero A, Gonzáles-Olvera J, Ruiz-García M, AvilaOrdoñez U, Vaugier V, García-Reyna JC. rTMS reduces focal brain hyperperfusion in two patients with EPC. Acta Neurol Scand 2004;109:290-296.

26. Brasil-Neto JP, de Araújo DP, Teixeira WA, Araújo VP, BoechatBarros R. Experimental therapy of epilepsy with transcranial magnetic stimulation: lack of additional benefit with prolonged treatment. Arq Neuropsiquiatr 2004;62:21-25.

27. Fregni F, Thome-Souza S, Bermpohl F, et al. Antiepileptic effects of repetitive transcranial magnetic stimulation in patients with cortical malformations: an EEG and clinical study. Stereotact Funct Neurosurg 2005;83:57-62.

28. Kinoshita M, Ikeda A, Begum T, Yamamoto J, Hitomi T, Shibasaki H. Low-frequency repetitive transcranial magnetic stimulation for seizure suppression in patients with extratemporal lobe epilepsy-a pilot study. Seizure 2005;14:387-392.

29. Rotenberg A, Bae EH, Takeoka M, Tormos JM, Schachter SC, PascualLeone A. Repetitive transcranial magnetic stimulation in the treatment of epilepsia partialis continua. Epilepsy Behav 2009;14:253-257.

30. Santiago-Rodríguez E, Cárdenas-Morales L, Harmony T, Fernández-Bouzas A, Porras-Kattz E, Hernández A. Repetitive transcranial magnetic stimulation decreases the number of seizures in patients with focal neocortical epilepsy. Seizure 2008;17:677-683.

31. Joo EY, Han SJ, Chung SH, Cho JW, Seo DW, Hong SB. Antiepileptic effects of low-frequency repetitive transcranial magnetic stimulation by different stimulation durations and locations. Clin Neurophysiol 2007;118:702-708.

32. Iyer MB, Schleper N, Wassermann EM. Priming stimulation enhances the depressant effect of low-frequency repetitive transcranial magnetic stimulation. J Neurosci 2003;23:10867-10872.

33. Brighina F, Daniele O, Piazza A, Giglia G, Fierro B. Hemispheric cerebellar rTMS to treat drug-resistant epilepsy: case reports. Neurosci Lett 2006;397:229-233.
34. Daniele O, Brighina F, Piazza A, Giglia G, Scalia S, Fierro B. Lowfrequency transcranial magnetic stimulation in patients with cortical dysplasia-a preliminary study. J Neurol 2003;250:761-762.

35. Fregni F, Otachi PT, Do Valle A, et al. A randomized clinical trial of repetitive transcranial magnetic stimulation in patients with refractory epilepsy. Ann Neurol 2006;60:447-445.

36. Theodore WH, Hunter $\mathrm{K}$, Chen $\mathrm{R}$, et al. Transcranial magnetic stimulation for the treatment of seizures: a controlled study. Neurology 2002;59:560-562.

37. Cantello R, Rossi S, Varrasi C, et al. Slow repetitive TMS for drug-resistant epilepsy: clinical and EEG findings of a placebocontrolled trial. Epilepsia 2007;48:366-374.

38. Inghilleri M, Gilio F, Conte A, et al. Topiramate and cortical excitability in humans: a study with repetitive transcranial magnetic stimulation. Exp Brain Res 2006;174:667-672.

39. Inghilleri M, Conte A, Frasca V, et al. Antiepileptic drugs and cortical excitability: a study with repetitive transcranial stimulation. Exp Brain Res 2004;154:488-493.

40. Fregni F, Boggio PS, Valle AC, et al. Homeostatic effects of plasma valproate levels on corticospinal excitability changes induced by $1 \mathrm{~Hz}$ rTMS in patients with juvenile myoclonic epilepsy. Clin Neurophysiol 2006;117:1217-1227.

41. Bindman LJ, Lippold OCJ, Redfearn JWT. The action of brief polarizing currents on the cerebral cortex of the rat (1) during current flow and (2) in the production of long-lasting after-effects. J Physiol 1964;172:369-382.

42. Lolas F. Brain polarization: behavioral and therapeutic effects. Biol Psychiatry 1977;12:37-47.

43. Nitsche MA, Liebetanz D, Antal A, Lang N, Tergau F, Paulus W. Modulation of cortical excitability by weak direct current stimulation--technical, safety and functional aspects. Suppl Clin Neurophysiol 2003;56:255-276.

44. Nitsche MA, Paulus W. Sustained excitability elevations induced by transcranial DC motor cortex stimulation in humans. Neurology 2001;57:1899-1901.

45. Nitsche MA, Nitsche MS, Klein CC, Tergau F, Rothwell J, Paulus W. Level of action of cathodal DC polarisation induced inhibition of the human motor cortex. Clin Neurophys 2003;114:600-604.

46. Nitsche MA, Jaussi W, Liebetanz D, Lang N, Tergau F, Paulus W. Consolidation of human motor cortical neuroplasticity by D-cycloserine. Neuropsychopharmacology 2004;29:1573-1578.

47. Nitsche MA, Grundey J, Liebetanz D, Lang N, Tergau F, Paulus W. Catecholaminergic consolidation of motor cortical neuroplasticity in humans. Cereb Cortex 2004;14:1240-1245.

48. Nitsche MA, Lampe C, Antal A, et al. Dopaminergic modulation of long-lasting direct current-induced cortical excitability changes in the human motor cortex. Eur J Neurosci 2006;23:1651-1657.

49. Lian J, Bikson M, Sciortino C, Stacey WC, Durand DM. Local suppression of epileptiform activity by electrical stimulation in rat hippocampus in vitro. J Physiol 2003;547:427-434.

50. Liebetanz D, Klinker F, Hering D, et al. Anticonvulsant effects of transcranial direct-current stimulation (tDCS) in the rat cortical ramp model of focal epilepsy. Epilepsia 2006;47:1216-1224.

51. Fregni F, Thome-Souza S, Nitsche MA, Freedman SD, Valente KD, Pascual-Leone A. A controlled clinical trial of cathodal DC polarization in patients with refractory epilepsy. Epilepsia 2006; 47:335-342.

52. Nitsche MA, Cohen LG, Wassermann EM, et al. Transcranial direct current stimulation: state of the art 2008. Brain Stimulation $2008 ; 1: 206-223$.

53. Wassermann EM. Risk and safety of repetitive transcranial magnetic stimulation: report and suggested guidelines from the International Workshop on the Safety of Repetitive Transcranial Magnetic Stimulation, June 5-7, 1996. Electroencephalogr Clin Neurophysiol 1998;108:1-16.

54. Siebner HR, Lang N, Rizzo V, et al. Preconditioning of lowfrequency repetitive transcranial magnetic stimulation with transcranial direct current stimulation: evidence for homeostatic plasticity in the human motor cortex. J Neurosci 2004;24:3379-3385.

55. Nitsche MA, Doemkes S, Karaköse T, et al. Shaping the effects of transcranial direct current stimulation of the human motor cortex. J Neurophysiol 2007;97:3109-3117. 